\title{
Primeros trazos infantiles: Una aproximación al inconsciente
}

\author{
Lorena \\ Antezana \\ Barrios "Es sobre todo en el dibujo donde el niño expresa más fácilmente sus quejas reprimidas, sus \\ agravios y sus odios. El dibujo brota más directamente del inconsciente y consigue así esconder a \\ su autor su verdadero contenido... No comprendiendo el sentido de sus dibujos y teniendo el mayor \\ interés en no revelarlo, el niño se siente inclinado más bien a rehusar que a ayudarnos a descifrar \\ el simbolismo en sus creaciones. Con un trabajo analítico se consigue, sin embargo, reconstruir, \\ gracias a esos dibujos en apariencia caóticos y dispares, una narración gráfica que conduce al \\ origen de estas producciones, al traumatismo afectivo y a los sentimientos reivindicadores que los \\ inspiraron". [2]" \\ Sophie Morgenstern
}

\section{La gráfica infantil}

El estudio del grafismo infantil como sistema de escritura autónomo frente a la subordinación a lo verbal, es un fenómeno de origen reciente aún no resuelto. Marisa Rodulfo[3], en un trabajo de investigación titulado "El niño del dibujo" constata que aún los autores que mayor espacio le otorgan al grafismo y a sus operaciones constructivas "niegan, sin embargo, su autonomía semiótica"[4]. Cuestiona a lo largo de la investigación, concepciones bastante arraigadas como la de la función expresiva del dibujo o la idea de que éste traduce una fantasía preexistente, o la de su ligamen forzoso y convalidador con la palabra y por ella.

Por otro lado, Francoise Dolto, recordaba sin cansarse a los terapeutas que en psicoanálisis no existe ninguna criptografía de interpretación a priori y que es necesario aprender los elementos del léxico básico de cada niño.[5]

Según lo planteado por Rodulfo, al momento presente, la desproporción textual es abrumadora; si se descuentan bellísimos y muy importantes fragmentos, es muy poco el espacio consagrado a la gráfica infantil en comparación con el que se dedica en psicoanálisis a lo verbal y al juego. Sobre todo si se toma en cuenta la elevada proporción de niños que espontáneamente instauran el dibujo como eje de su producción durante un tratamiento psicoanalítico. Sin hablar de que el dibujo infantil es prácticamente ignorado en otros espacios.

Para acceder al inconsciente del niño debemos considerar la estructuración peculiar de su aparato psíquico. Al aproximarse al pequeño paciente es necesario reformular el descubrimiento freudiano de la asociación libre en su forma elocutiva, precisamente en razón de que el aparato psíquico no es un sistema atemporal y, según cuando se aborde exige variaciones de procedimiento.

Para trabajar con niños, se tuvo que reencontrar las cadenas asociativas a través de los distintos materiales de los que se puede valer un niño, ya que, así como se lo ha definido "perverso polimorfo" en lo pulsional, también es mucho más polimorfo en sus medios de expresión y la primacía del lenguaje verbal no está en él asentada como suele serlo una vez dejada atrás la adolescencia.

"Un niño expresa por medio de gestos, posturas, dibujos, modelado o música la imagen interior de su fantasía. Todo ser humano simboliza por medio de fantasías auditivas, gustativas, olfativas, tactiles y visuales pero puede expresarlas de otro modo que por la palabra".[6]

Al situarse frente a cualquier escritura en imágenes (trátese del grafismo, del modelado 0 incluso de aquello que en el juego mismo concierne a lo imaginario visual) se debe ser 
consecuente con los procedimientos metodológicos construidos en los comienzos del psicoanálisis, justamente a propósito de un fenómeno como el del sueño que sólo devino "vía regia" para acceder al inconsciente cuando se lo pudo imaginar como una escritura en imágenes.

Se puede decir que el arte y el sueño son dos dialectos diferentes pero no opuestos. Diferencias aparte, dibujo y sueño se anudan en un elemento en común que es la consideración por la figurabilidad, nombre que Freud da a lo figural como región autónoma de escritura, con sus espesores y particularidades irreductibles. Consideración por la figurabilidad es tanto como decir lo que la imagen tiene de irreductible a otra escritura que no sea ella misma, lo que no se puede decir sino a través de su propia diferencia, lo que no es traducible sin el resto decisivo de sus propios lazos.

\section{Escritura del cuerpo}

Sami-Ali en "El espacio imaginario", es de los pocos psicoanalistas que se detienen a reflexionar sobre ese espacio tan singular y tan ingenuamente dado por sentado una vez que se lo ha adquirido que es la hoja de papel: derecha e izquierda, arriba y abajo en esa hoja repetirán en sus transposiciones vicisitudes más arcaicas del cuerpo en el espacio, pero con no menos valor constituyente. Por otra parte, Sami-Ali procede a un fino inventario que en sí mismo tiene además valor de diagnóstico diferencial, de diversas modalidades del grafismo, distinguiendo cuatro variantes perfectamente oponibles:

El dibujo como clásica realización del deseo en el sentido estrictamente freudiano de "La interpretación de los sueños". Lo que Sami-Ali es capaz, no sólo de destacar sino de llevar más lejos es el énfasis en el cuerpo propio en tanto mediador y vehículo de dicha realización.

Una posibilidad del dibujo que constituye uno de los descubrimientos más interesantes de este autor, en sí misma es una jerarquización de la producción gráfica al develarnos complejidades insospechadas en ella; a la negatividad en lo figural, a aquellos dibujos en donde lo esencial reside en lo que se omite, en el vacío que los articula.

El espacio de la hoja en blanco es susceptible de funcionar, por otra parte, como un espejo que refleja la imagen misma del sujeto lo cual, debe el analista descubrir en cada caso, localizando con respecto a qué producciones del niño les corresponde esta conceptualización.

El espacio en donde se desarrolla la actividad gráfica puede confundirse, además, con la espacialidad del cuerpo propio.

Francisco Tosquelles,[7] (1958) en un trabajo sobre el dibujo infantil del niño retrasado, se interesa en niveles mucho más abarcativos que los técnicos, abriendo el camino para una consideración del graficar como medio de escritura del cuerpo, a la vez que como medio de lectura para el psicoanalista que debe evaluar no sólo el estado psíquico de ese determinado niño en lo que se refiere a una problemática puntual, sino el grado de desarrollo alcanzado en la conformación del aparato psíquico, más allá o más acá de tal o cual contenido inconsciente.

Hablar de narración gráfica en una época en la que la semiótica de la imagen aún esperaba su hora de florecimiento, era llevar el asunto teóricamente lejos. Hoy, con los conocimientos adquiridos en semiótica, se cuenta con una herramienta analítica capaz de dilucidar y entender el dibujo infantil.

A pesar del trabajo que ya se ha realizado en psicoanálisis para la comprensión del grafismo infantil, donde se han hecho pequeños seguimientos de los dibujos de niños que acceden a psicoterapia y durante el tiempo de tratamiento, no se han tomado largos periodos de producción gráfica que es lo que se pretende abordar en esta investigación. 
En recientes estudios clínicos, Ricardo Rodulfo[8] conceptualiza tres puntos de inflexión en la estructura de la subjetividad, puntos de inflexión que gravitan en relación con tres espacios fundamentales que el autor designa como lugares de aposentamiento para dicha subjetividad, respectivamente:

cuerpo

materno espejo

- hoja de papel

En cada uno de estos lugares de aposentamiento hay que considerar la interacción compleja y recíproca de los registros de lo real, lo Simbólico y lo Imaginario, propuesta por Lacan.

Por otra parte, estos lugares no están dados, no le son prefabricados generosamente al niño, en realidad este debe construirlos con los materiales de su constitución biológica sumados a los materiales ofrecidos por el mito familiar a través de las funciones materna, paterna, fraterna, etc. La paradoja es que al erigir estos lugares para anidar va produciendo simultáneamente su propia corporeidad en tanto que subjetiva.

El niño, desde el momento de su nacimiento, ha de atravesar múltiples peripecias para constituirse en sujeto apuntalado en el organismo, pero irreductible a él. Recorrido laberíntico, entramado por marchas y contramarchas, escandido por detenciones, tanto como por saltos pronosticables pero impredecibles en su dirección última. Recorrido no atravesado jamás linealmente ni de una vez para siempre y, ante todo, diferente siempre, nunca idéntico a otro.

Y un día, primeros dibujos, apertura al papel. Se constata una diferencia cualitativa importante con todo lo anterior. Estas primerísimas producciones gráficas, figurales, al tiempo que inician una profunda inflexión en la subjetividad sin precedentes, nos permiten, al retomar en un nuevo ámbito viejas problemáticas ya liquidadas o al menos medianamente atravesadas en otras instancias, algo que podemos asimilar a obtener verdaderas "fotografías"... de momentos pretéritos, de combates apenas extinguidos, que se actualizan ante el papel aún vacío o aún por constituir y un abanico de colores.

Espacio blanco que se poblará de marcas, trazos, archiescritura... letra, en fin, bajo las apariencias del mamarracho en desorden. ¿Hecho simple del crecimiento? Antes bien, resonante acontecimiento vital; he aquí la pulsión encarnada en lo que antes de su paso era una simple "caja de pinturitas".[9]

En esta experiencia del niño de dar a luz sus primeros balbuceos de trazo, se recurre al concepto de magma[10], que correspondería a las sensaciones más arcaicas que desembocan en la representación gráfica. Se trata de formaciones figurales aún no figurativas, compuestas por trazos que en su futura geometrización se volverán líneas y círculos, masas que tienden al óvalo, vacías a veces, llenadas otras, pero siempre sin verdadera diferenciación interna.

Estas producciones sin argumento son cuerpo transpuesto y sirven para darnos una idea de las primerísimas vivencias del recién nacido. Por supuesto, estos trazados tormentosos están aún lejos de constituirse en una imagen del cuerpo reconocible por el niño como tal, se trata de fragmentos en curso de diferenciación.

En investigaciones empíricas realizadas a partir de dibujos infantiles se observa que la mayoría de los dibujos no plantean un objeto real concreto, se trataría más bien de un espacio onírico que reflejaría las amenazas virtuales o reales del mundo externo; el conflicto entre el mundo interior y el mundo exterior se configuran como instancias inconscientes, no son situaciones concretas, es una estructura, una red de relaciones que no tienen una relación causal.[11]

Un niño en etapa pre-escolar está recién ingresando en el mundo de las palabras, situación que incluso con su ingreso a un establecimiento de educación formal a los seis años no está 
completamente resuelta. El estudiar la producción gráfica de un niño, entre los dos y los seis años, utilizando los códigos propuestos por Rafael del Villar para la comprensión de textos visuales, abre una nueva vía de aproximación a un tipo de lenguaje infantil utilizado por los niños como medio cotidiano de expresión.

Los antecedentes y la utilización de las gráficas infantiles, nos permitieron realizar la selección de dibujos que se analizaron. Se procuró que esta selección considerara un número adecuado de dibujos, así como una suficiente variedad de los mismos de manera que dieran cuenta de las diversas etapas de desarrollo vividas por el pequeño, en el periodo que comprende esta investigación.

Como herramienta de análisis gráfico - visual en el tratamiento de los dibujos aplicaremos la semiótica, como constructora de sentido a través de la interrelación códica.

\section{Los primeros dibujos de Diego}

A partir de estos antecedentes, y seleccionando los dibujos de un niño, Diego, se realizó un estudio descriptivo y explicativo de la información semántica y pulsional inconsciente que se desprendía de la serie de dibujos elaborados por él pequeño entre los 2 y los 6 años. En este artículo se tomará la primera fase de dibujos realizados (tres periodos: 1 a 2 años, 2 a 3 años y 3 a 4 años).

Los elementos que más se destacan en el análisis de la materialidad significante (primera etapa), en el que se tomaron dos dibujos ( 1 Y 2), son las similitudes encontradas en relación al manejo de los códigos, especialmente en los códigos de planos, cromas, líneas y manejo espacial. Y de estos daremos cuenta a continuación.

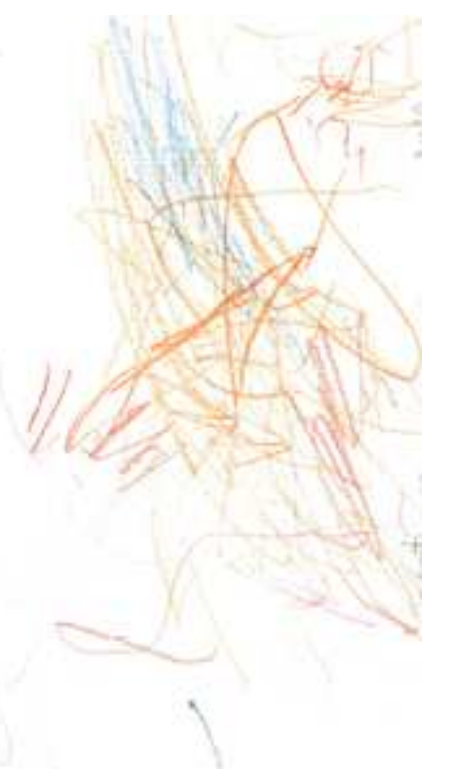

figura 1



figura 2

El niño trabaja utilizando dos encuadres. A nivel de los planos utilizados el que describiría el "entorno" es un poco más lejano (plano medio o general), mientras que el que se refiere al "sujeto" es más cercano (primer plano). Cabe hacer notar en este punto que, al no existir narración en estos primeros "escritos" la separación entre lo que denominamos sujeto y entorno responde a fines meramente analíticos y está dada por la intensidad de los trazos. De esta forma se presume que lo más intenso es lo más cercano al sentir del niño por lo que representaría el sujeto.

En cuanto a lo cromático, utiliza muchos colores, aunque los colores más fuertes (rojo y negro) cumplen la función de mediación, es decir están presentes en ambos espacios 
(entorno/ sujeto) Llama la atención el uso armónico que hace el niño del color, estableciendo un equilibrio cromático en cada área, aunque en esta primera etapa hay un colorido más cálido en relación al entorno, correspondiendo la intensidad, el primer plano con los colores más oscuros.[12]

El trabajo lineal resulta ser el eje ordenador de esta primera etapa donde claramente las líneas curvas son más difíciles de lograr, su producción es un tanto "artificial", el niño trata de seguir el orden establecido pero esto no es fácil.

En los dos dibujos analizados existe una inversión en el tratamiento del encuadre y de la angulación de toma, quizás esta marcada diferencia habla de un no reconocimiento del niño, él no sabría claramente donde se encuentra, aún no es capaz de distinguirse como sujeto, no existe mucha diferenciación entre él y lo otro (madre, mundo).

En cuanto a la categoría de sentido que se desprende de la materialidad significante, aunque existen algunas correspondencias en ambos dibujos, a un determinado código no le corresponde necesariamente un determinado sentido. Son los propios dibujos los que establecen el marco de interpretación de sentido y este viaja en un código u otro indistintamente. En ambos dibujos existe una diferencia notoria en relación al foco de atención del niño; mientras que en el primero su presencia como sujeto es menos conflictiva, más íntima, en el segundo claramente se vislumbra incomodidad en relación a su situación en el mundo. Hay más fuerza en el segundo dibujo, más rebeldía, deseo de libertad, rabia contenida que explota sobre el papel.

Los códigos que san más claramente cuenta de la pulsión, en ambos casos son el cromático, lineal y espacial, son los que soportan la tensión y existe una relación inversa en ambos dibujos donde a pesar de que el niño no está cómodo al principio llega a encontrar el punto de partida hacia el equilibrio, mientras que en el segundo dibujo es a la inversa, el niño empieza a gusto pero termina muy tenso, hay displacer, está forzado.

La estructura profunda expresa el cambio que se produce en el niño en relación a un primer conflicto de adaptación. Por un lado el aceptar el orden externo, las reglas impuestas por los padres conlleva a un repliegue del sujeto, un cortarse las alas, lo que le provoca tensión al tratar de ser más coherente con él mismo y rechazar la ley de los padres, ley que en el fondo debe aceptar para sentirse protegido porque no sabe como operar frente al mundo.

En síntesis:

Aceptación orden externo - Aceptación orden externo - rechazo orden externo

Repliegue de su propio ser - Negación de su ser - Aceptación de su ser

Este es un conflicto que se inicia, el niño lo plasma en el papel, lo siente, pero no alcanza aún a darse cuenta de él, no tiene cómo resolverlo.

En relación a la historia de vida en esta etapa el elemento que podría generar el primer conflicto es el dejar el espacio en el que el niño se desenvolvía cotidianamente (la casa de familia donde era cuidado) para ingresar a otro espacio con nuevas reglas (jardín infantil), lo que le genera angustia que es manejada en forma agresiva.

La segunda etapa a describir corresponde a 1996, se tomaron dos dibujos como muestra: $\mathrm{n}^{\circ} 3$ $\mathrm{y}^{\circ} 4$. El primero corresponde a pintura con acuarela, mientras que el segundo es un pegoteo (plasticina sobre papel). 


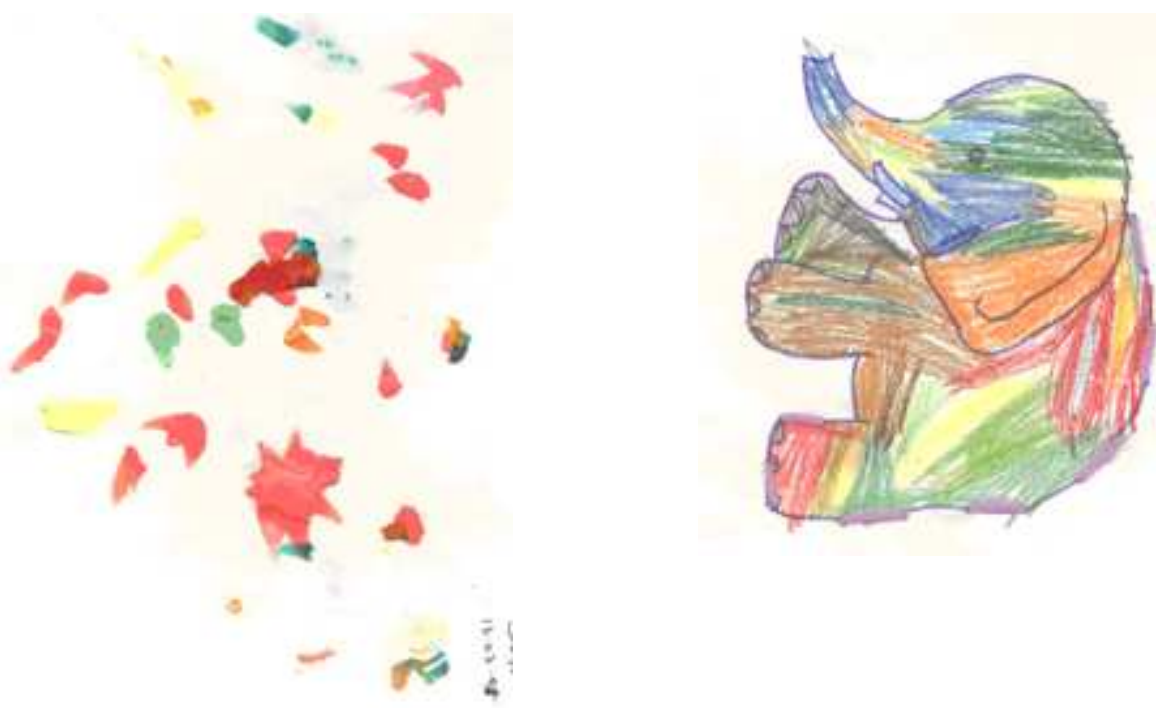

figura 2

figura 4

En relación a la materialidad significante, los códigos que presentan más diferencias son: el código cromático donde en el primer dibujo hay poco contraste y los colores utilizados son mas bien oscuros, mientras que en el segundo la gama cromática es mayor, resalta la fuerza del color, la viveza.

A nivel lineal (sólo en el primer dibujo por que en el segundo lo que se describe es la textura), la distinción está dada por la forma de utilizar la línea (si es sólo para distinguir una figura del fondo, o un contorno), las líneas son gruesas; en relación ala textura la mayor o menor concentración de plasticina es la que marca la diferencia. En ambos dibujos el trabajo es tosco.

A nivel narrativo, en el primer dibujo existe una oposición entre el niño y la naturaleza (representada por un árbol y una flor[13]), en el segundo no hay narración. La utilización del espacio asignado sigue siendo interesante pues en ambos dibujos utiliza un 75\% del mismo.

En cuanto a las categorías de sentido que se deducen, a nivel general se percibe un cambio cualitativo importante en relación a la percepción del niño del mundo y su posición en él. Mientras que en un principio lo que prima es lo externo, es decir que el niño es parte del mundo, sin mayor separación, poco importante, desplazado, disminuido, vacío en relación al mundo adulto que lo ocupa y llena todo; en el segundo dibujo el pequeño comienza a tomar conciencia de sí mismo, a reconocerse como sujeto, aunque este reconocimiento es aún precario. Se sientan las primeras bases de su mirada como individuo. El niño está vuelto hacia dentro, reconociéndose, tomando conciencia de si, en una etapa de "estancamiento", de cierre, de construcción desde adentro.

En relación a la energía, pulsión, que se desprende de los dibujos, los puntos donde se concentra la tensión están dados a través del código cromático y de planos. Además en el primero también contribuyen los códigos lineal y narrativo, mientras que en el segundo el espacial y la textura. Esto es comprensible si se toma en consideración la materia de la que están hechos los dibujos. El proceso que vive el niño es menos fuerte que en la etapa anterior, es tiempo de cambio pero no de crisis, hay una continuidad pulsional, un cierto equilibrio aunque la tensión se encuentra latente.

La estructura profunda refleja el cambio de etapa del niño. Al principio se encuentra solo, desplazado por la presión externa, sin reconocerse. Más adelante se empieza a concentrar en sí mismo iniciando un proceso de reconocimiento y diferenciación con lo externo. Se reconoce sujeto. Su interés está focalizado, es selectivo. No existe conflicto.

En síntesis: 
Niño = mundo - Concentración en sí mismo - Proceso de incorporación del mundo

Vacío Reconocimiento sujeto

Contrastando esta fase con la historia de vida, las condiciones en las que se desarrolla no ha variado notoriamente, se mantienen constantes. Sigue en casa de sus abuelos, va al mismo jardín infantil, el rol paterno lo sigue ejerciendo su abuelo, lo que se relacionaría con la tranquilidad que se desprende de sus dibujos, un proceso de crecimiento no conflictivo.

La tercera etapa corresponde a la creación de 1997, la muestra está formada por dos dibujos (5 Y 6); uno que está sólo pintado y otro que está hecho de papeles pegados[14].

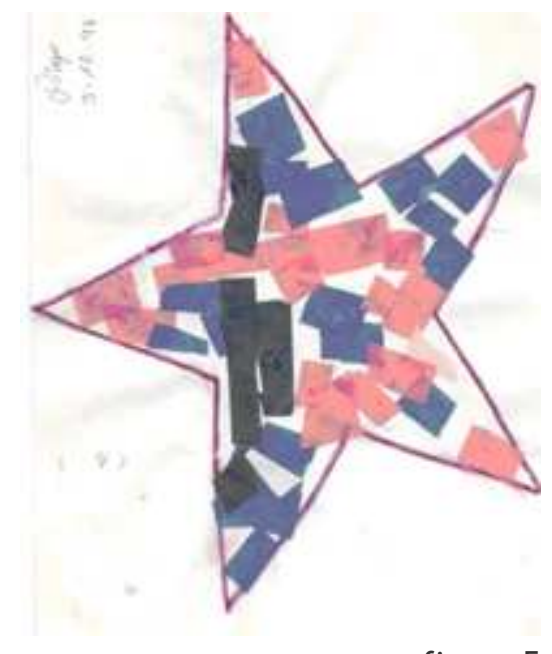

figura 5

En relación a la materialidad significante en ambos trabajos los códigos son utilizados de la misma manera. Las mayores coincidencias están dadas en el código del encuadre (continúa utilizando dos y mantiene la línea cielo - tierra, angulación de toma donde a un punto de vista frontal se opone un picado; los planos, utilizando un primer plano en ambos.

En el código narrativo, la descripción realizada se basa en lo que siente el niño, ya que no existe una historia propiamente tal, a nivel cromático se oponen los colores oscuros y fuertes (rojo, azul) con los claros (verde claro, naranja, rosado y celeste), los colores oscuros aún son mayoría en el entorno.

En relación a la categoría de sentido, el mundo exterior (adultos, la ley del padre) sigue siendo dominante, es el espacio formal, ordenado, rígido que exige obediencia, el niño siente que debe adaptarse a él y que debe superar su desorden natural, la informalidad en la que se desenvuelve. El niño se convierte en su propio juez, su nivel de autoexigencia es alto, no se siente cómodo. Por otro lado, ese mismo mundo ordenador le da seguridad, implica lo conocido.

El niño es menos selectivo, hay un retroceso en ese ámbito, todo vuelve a ser importante, hay nuevamente un vuelco hacia fuera.

Sobre la pulsión que se desprende de estos dibujos, los códigos cromático y la angulación de toma son coincidentes y decidores: el niño sufre una presión constante, tratando de hacerlo bien, de anularse incluso para lograrlo. La tensión se acumula pero no explota, se está concentrando. Al parecer se trata de una etapa difícil, de un sacrificio del que no alcanza a darse cuenta.

La estructura profunda revela la aceptación del orden externo, la incorporación de reglas a su espacio interior. Es el drama de "un ser que debe dejar de ser para ser", se anula, no ve 
espacios de libertad, no sabe resolver la paradoja: ese mundo que lo castra es reconocido como fuente de seguridad y confianza, y al aceptarlo completamente va dejando de lado su propio ser.

En síntesis:

Acepta reglas externas / Incorpora reglas a espacio interior

Acepta seguridad y confianza Deja de lado su propio ser

\section{Externos}

Vinculando su historia de vida, Diego tiene en esa época tres años y hay dos experiencias fuertes que le tocan vivir que pueden justificar su necesidad de apoyarse en la seguridad y confianza de los "grandes": Por un lado un viaje a Europa, donde lo que sabía a nivel de lenguaje no le era de ninguna utilidad ya que no lo entendían. Su angustia por no poder comunicarse fue grande. La otra experiencia fuerte está asociada con el reconocimiento de la existencia de su padre con el que empieza a hablar por teléfono y cuya presencia espera con ansias. Se confunde por que no sabe como debe seguir operando (hasta ese momento su abuelo cumplía el rol de padre y luego se da cuenta de que tiene un papá y que no está cerca).

Sin pretender cerrar el tema o agotarlo sólo me resta plantear algunas inquietudes, más que presentar conclusiones o cerrar el diálogo.

\section{A modo de cierre}

Queda en evidencia, a lo largo de este estudio, la necesidad de realizar más estudios e investigaciones en relación al valor de la expresión gráfica infantil. No nos ha sido posible contrastar las etapas propuestas por Piaget con la evolución de los dibujos del niño, esto porque las pruebas planteadas por Piaget son una batería de test y una de las partes trata del dibujo en sí, donde se pide al niño que dibuje determinadas formas.

Saber si los tiempos acordados entre una etapa y la siguiente se han acelerado en nuestros días, implicaría conocer cuál es el parámetro real que se está considerando como producto "normal" para un niño en la etapa de la que se trate. Información que para el caso de Chile, lugar de proveniencia y de desarrollo del niño, no existe.

Sin embargo, como no contamos con una escala comparativa en relación al desarrollo cognoscitivo de los niños en este periodo histórico, estas observaciones carecen de validez.

Lo anterior nos obliga a realizar una precisión en relación a lo que se está estudiando: todos los resultados de esta investigación aluden a un caso específico, y no deberían ser generalizados, sin antes contar con mayor investigación al respecto.

El trabajar con la producción gráfica de un niño, en sus primeras etapas de desarrollo permiten encontrar ciertas claves de funcionamiento particulares, y rasgos esenciales que caracterizan a ese pequeño, con estos, y a la luz de los resultados es posible postular que el dibujo infantil nos provee de valiosa información en relación a la constitución de su inconsciente, rasgos que se escapan a la simple observación, conflictos que no son vistos y que exigen prestar más atención.

Importante sería el incluir en una investigación futura la observación de la forma de dibujar del niño, el cómo toma los lápices, cómo se concentra en el dibujo, cómo posiciona la hoja y va llenando de trazos el espacio en blanco, junto a la observación de su forma de jugar, y sus primeras palabras. 
Ordenando los dibujos del niño en relación a las etapas propuestas por Piaget, tenemos:

\begin{tabular}{|l|l|l|}
\hline PIAGET & $\begin{array}{l}\text { Fase sensorio } \\
\text { motriz(0 - 2 años) }\end{array}$ & $\begin{array}{l}\text { Fase } \\
\text { preconceptual (2 - } \\
4 \text { años) }\end{array}$ \\
\hline NIÑO & $\begin{array}{l}\text { Primera y Segunda } \\
\text { Etapa }\end{array}$ & $\begin{array}{l}\text { Tercera y Cuarta } \\
\text { Etapa }\end{array}$ \\
\hline
\end{tabular}

De esta tabla de referencia y contrastando el análisis efectuado para cada una de las etapas podríamos decir que, efectivamente, hay un manejo expresivo y simbólico en los dibujos del niño, en los trazos, en la seguridad con la que maneja el lápiz, en la precisión de los detalles que no está acorde con lo planteado por Piaget, y que entonces, el acceso del niño a otro tipo de estímulos visuales y tecnológicos habrían acelerado su desarrollo cognoscitivo.

El dibujo del niño es un tipo de escritura pero requiere una forma específica de lectura (una competencia ), ya que no se trata de una traducción de colores o de formas. El dibujo del niño, como todo otro sistema de imagen no es el reflejo de la realidad sensible. No es más que la transposición simbólica en un orden de signos, en un sistema semiológico. Estos significantes se articulan entre ellos según principios que es posible desprender con un análisis estructural.[15]

El dibujo en esto se asemeja a la caricatura, y también a la agudeza, prestándose a los mecanismos de condensación y desplazamiento, aparece como un material privilegiado para servir de escape a los deseos inconscientes.

En el psicoanálisis, lo que define la proyección, es el desplazamiento que constituye uno de los mecanismos fundamentales de defensa contra lo que no podemos admitir. En otros términos, cuando un niño cuenta lo que ve en una imagen de formas ambiguas, proyecta literalmente su manera de ver. Por esta razón el dibujo constituye, en cierta manera, una prueba proyectiva, ya que proyecta la "visión" del niño.

Esto resulta particularmente importante cuando aquí tratamos de un niño pequeño, que aún no tiene toda la capacidad verbal que requeriría para poder describir lo que siente, él no es capaz de hacer esta traducción y el dibujo está diciendo más de lo que le pasa y de lo que vive que sus propias palabras.

El dibujo registra el estado emocional y se nota por ejemplo el rasgo iracundo y agresivo que puede llegar al límite de rasgar el papel, o el rasgo oscilante apenas acusado.

Muchos autores se interesan por la disposición de los rasgos en el espacio, dicen que el predominio de las líneas rectas son el reflejo de determinados aspectos de la personalidad, sin embargo creemos que es el estudio del conjunto del grafismo el que ayudará a crearnos una opinión. Las deducciones que podemos hacer del estudio de los círculos o de los ángulos deben integrarse en una observación más global del dibujo.

En cada detalle, el dibujo lleva la marca de la vida emocional del niño. Si se considera el dibujo en su conjunto, podemos decir que refleja una vista de conjunto de la personalidad.

La elección de los objetos, está frecuentemente unida a las circunstancias pero depende igualmente de las predilecciones habituales. Se trata de objetos que están ligados a su mundo cotidiano, y sobre todo al de sus libros, seriales y películas favoritas, los cuentos y relatos que le afectan más y finalmente de sus sueños.

El valor narrativo en el dibujo además de las referencias de actualidad tiene una significación simbólica. Nos muestra la manera en que el niño vive las significaciones simbólicas que les atribuye, a través de las cosas. Se refleja en su dibujo el conjunto de su mundo imaginario. 
Lo que no puede decirnos de sus sueños, de sus emociones en las situaciones concretas, nos lo indica por su dibujo.

El punto de vista psicoanalítico aparece cuando, estudiando el contenido de los dibujos del niño, vemos que la elección de ciertos objetos, de ciertos temas, de ciertas particularidades estilísticas son inexplicables para él. No se puede hablar ya entonces de su valor narrativo, sino considerando que la historia contada se inscribe en un registro de pensamientos diferentes del sistema de pensamiento consciente.

\section{En síntesis}

El análisis de los dibujos de Diego permite visualizar herramientas concretas de trabajo con la gráfica. En su crecimiento, al igual que en el de millones de niños, manifiesta contradicciones, tensiones y puntos críticos que, sin dejar de ser "normales" pueden dar pistas apropiadas para entender sus rasgos constitutivos. Explorar sobre cómo reacciona ante diferentes situaciones, la manera en que maneja las tensiones que en mayor o menor grado seguirán operando, la visión de mundo que empieza a construir y otras experiencias tempranas que formarán parte de una matriz subyacente que le de sentido a su vida son una invitación a seguir con esta exploración.

Los dibujos de un niño son un diario de vida abierto a quien lo pueda leer, nos cuentan sobre sus temores, sus rabias, sus inseguridades y penas, nos hablan de una etapa de constitución temprana difícil de entender, de vivir. Son escritura del cuerpo, de un cuerpo que va cambiando, que va creciendo, que se va socializando, cortando las alas o aprendiendo a volar y que no debemos desconocer, si queremos apoyar el crecimiento "sano" y equilibrado de nuestros niños, futuro del mundo.

Se hace necesario seguir investigando en torno al lenguaje gráfico que sin saberlo utilizan los niños, de manera de estructurar una metodología que permita su "lectura". Esto podría abrir las puertas al diseño de estrategias de prevención temprana, a la detección de patologías o problemas que pudieran desencadenarse más tarde $\mathrm{y}$, sobre todo, crear la inquietud de que el dibujo infantil debe ser trabajado de manera más rigurosa.

A nivel de educación pre escolar cabe preguntarse ¿cuánto es posible saber de los niños con los que trabajamos a través del dibujo?, este elemento unido al juego es un material de enorme valor que no podría estar ausente de los planes de estudio de quienes trabajan directamente con menores.

Otro tema importante de incorporar es el cambio cognoscitivo que implica el acceso a las nuevas tecnologías pues, cada vez con más frecuencia, los modos de mirar y producir en los niños van cambiando, adquiriendo nuevas competencias y destrezas que es necesario tomar con los instrumentos apropiados.

\section{Bibliografía:}

Antezana, Lorena "Lecturas de una imagen pictórica", Tesis para optar al grado de Licenciado en Comunicación Social, Universidad de Chile, 1997

Antezana Lorena "Dibujo infantil: una escritura del cuerpo", Tesis para optar al grado de Magíster en Comunicación Social, Universidad de Chile, 2001

Brée, Joel "Los niños, el consumo y el marketing", Ediciones Paidós, España, 1995.

Camarena, Elba "El imaginario simbólico del niño en el dibujo", Tesis para optar al grado de Magíster en Comunicación Social, Universidad de Chile. 1995. 
Dolto, Francoise "Seminario de psicoanálisis de niños", Siglo XXI editores s.a. de c.v., México, 1998. 6ª edición.

Jara, Mirta "La sintaxis de los dibujos de los niños", Tesis para optar al grado de Magíster en Comunicación Social, Universidad de Chile.

Maier, Henry "Tres teorías sobre el desarrollo del niño: Erikson, Piaget y Sears", Amorrortu Editores, Buenos Aires, 1965.

Piaget, Jean "Seis estudios de Psicología", Editorial Labor S.A. , Buenos Aires, 1975

Piaget, Jean y otros, "Los años postergados. La primera infancia", Editorial Paidós, Unicef., Barcelona, 1984.

Rodulfo, Marisa "El niño del dibujo", Editorial Paidós. Argentina, 1993.

Soler, Pere "La investigación cualitativa en marketing y publicidad", Editorial Paidós. España. 1997

Taylor S.T., Bogdan, R. "Introducción a los métodos cualitativos de investigación", Editorial Paidós. España. 1996.

Valles S., Miguel "Técnicas cualitativas de investigación social", Editorial Síntesis. España. 1999

Widlocher, Daniel " Los dibujos de los niños", Editorial Herder. Barcelona. 1988.

\section{Notas:}

[1] Este artículo es parte de una investigación mayor "Dibujo Infantil: una escritura del cuerpo" realizada por la autora como trabajo de tesis conducente a la obtención del grado de Magíster en Comunicación Social.

[2] Rodulfo, Marisa. "El niño del dibujo", Paidos, 1993. p.40

[3] Psicoanalista de larga trayectoria, Coordinadora Docente del programa de actualización de Postgrado en Psicoanálisis con niños y adolescentes y profesora asociada de clínica de niños y adolescentes de la Universidad de Buenos Aires.

[4] Marisa Rodulfo Op.cit. p.11

[5] Dolto, Francoise, "Seminario de psicoanálisis de niños", Siglo XXI editores, p.12

[6] Dolto, Francoise. Op.cit.p.22

[7] Rodulfo, Marisa. Op.Cit. p.p. 40- 41

[8] Rodulfo Marisa y Ricardo, "Clínica psicoanalítica en niños y adolescentes", Buenos Aires, Ed.Lugar, 1986.

[9] Rodulfo, Marisa. Op.Cit. p.75

[10] Término y modelo utilizado en geología, se trata de una masa roja fundida, de grado líquido, que contiene en sí misma de una manera radicalmente inestable elementos en estado sólido y gaseoso. Infraestructura de la corteza terrestre, corresponde a lo originario de lo cual, en formaciones sucesivas, se va desprendiendo el resto, a través de pequeñas y grandes catástrofes.

[11] Del Villar, Rafael. "Protocolos interpretativos empíricos de la japoanimación".p.15

[12] V. Dibujo $N^{\circ} 1$

[13] v. Dibujo No 3

[14] V. Dibujo Nº

[15] Op.Cit P. 93 